\title{
Is the Optimal Labor Income Tax Progressive in a Unionized Economy?*
}

\author{
Thomas Aronsson and Tomas Sjögren \\ Department of Economics, Umeå University \\ S - 90187 Umeå, Sweden
}

April 2002

\begin{abstract}
This paper concerns optimal nonlinear labor income taxation in an economy with union wage setting and endogenous hours of work. The government is assumed to act in accordance with a utilitarian objective function. The main purpose of the paper is to study the determinants of tax progression and, in particular, to relate tax progression to the choice of work hours. We show how the optimal degree of tax progression depends on the incentives underlying the choice of work hours, as well as on whether or not the government can monitor the wage rate via tax policy. If the wage rate is chosen by the union member with median seniority, in which case the wage rate will be fixed under certain conditions, the marginal tax rate is unambiguously positive and the tax structure unambiguously progressive. If, on the other hand, the union acts according to the utilitarian framework, we can no longer in general rule out regressive tax systems. We also show that the tax system is more likely to be progressive if the individual union members freely choose their hours of work conditional on the wage rate, than if the union is able to directly affect the hours of work per employee.
\end{abstract}

Key words: Optimal taxation, labor supply, union wage setting

JEL classification: H21, J22, J51

\footnotetext{
* The authors would like to thank Magnus Wikström for helpful comments and suggestions.
} 


\section{Introduction}

The effects of labor tax progression in terms of wage rates and employment depend on the underlying structure of the labor market. If the labor market is competitive, the traditional view is that a progressive income tax system discourages employment via the labor supply decision. ${ }^{1}$ If, on the other hand, the labor market is dominated by trade unions and the hours of work per employee are fixed, several studies have found that an increase in the progression of the tax system tends to reduce the wage rate and increase employment. ${ }^{2}$ This is so because higher tax progression makes increases in the wage rate more costly in terms of lost employment from the point of view of the unions.

Previous studies on optimal taxation in unionized economies have mainly been concerned with flat tax rates $^{3}$, whereas the question of efficient nonlinear taxation has received little attention. One exception is Fuest and Huber (1997), who solve the optimal tax problem of a utilitarian government ${ }^{4}$ by using a model where the labor supply per employee is fixed. Their results suggest that the optimal tax system may be either progressive or regressive. In general, the optimal degree of tax progression - measured as the marginal tax rate over the average tax rate - depends on a variety of factors such as the wage elasticity of the labor demand, the distribution of bargaining power and the existence of unemployment benefits. Similarly, Aronsson and Sjögren (2001) consider optimal taxation and provision of public goods in the context of a mixed tax problem, where the hours of work are endogenous, and the set of tax instruments consists of a nonlinear income tax and linear commodity taxes. Their main contribution is to derive policy rules for the tax instruments and the public good under union wage setting. They do not explicitly relate the degree of tax progression to imperfect competition in the labor market.

The purpose of this paper is to study the optimal degree of progression of the labor income tax in a unionized economy. We assume that the government faces a utilitarian objective.

\footnotetext{
${ }^{1}$ See e.g. Sandmo (1983).

${ }^{2}$ See Layard (1982), Hersoug (1984), Malcolmson and Sartor (1987), Hoel (1989), Lockwood and Manning (1993), Holmlund and Kolm (1995) and Aronsson et al (1997).

${ }^{3}$ See, for example Palokangas (1987), Boeters and Schneider (1999) and Koskela and Schöb (2000).

${ }^{4}$ More specifically, they assume that the objective of the government is a generalization of the utilitarian objective function.
} 
However, contrary to the study by Fuest and Huber (1997), the hours of work per employee are assumed to be endogenous. The analysis is based on a general equilibrium model, where the number of employed persons and the hours of work per employee are perfect substitutes in the production function. We also distinguish between two different descriptions of the labor market; one in which the union acts in accordance with the seniority model of Oswald (1993), and the other where the union has a traditional utilitarian (or expected utility) objective. In the seniority model, the number of employed persons do not enter the objective function of the union, and the government will not be able to monitor the wage rate via the labor income tax under certain conditions. On the other hand, if a utilitarian union characterizes the labor market, the wage rate will be a function of the policy instruments. This distinction is interesting in the sense that the optimal tax policy depends on the channels through which taxation influences the employment.

To be able to focus on the relationship between tax progression and the labor market in a unionized economy, we will not consider asymmetric information or other motives for tax progression that also apply under perfect competition. Instead, the motives for tax progression discussed here are due to imperfect competition in the labor market. The paper contributes to the literature in primarily three ways. The first is by relating the optimal degree of tax progression to the choice of work hours. As far as we know, this aspect of tax progression has not been analyzed in previous studies on optimal taxation in unionized economies. If employed individuals choose their hours of work conditional on the wage rate, then work hours will be determined by individual preferences and constraints. In an economy with unemployment, this means that the employed individuals do not consider the tradeoff between the number of employed persons and the hours of work per employee. As such, there is an external effect associated with the choice of hours of work, which provides an incentive for the government to use a progressive tax system to increase employment by lowering the hours of work per employee.

The second contribution is to relate the optimal degree of tax progression to union objectives and, in particular, to whether or not tax policy influences the wage rate. We show that if the union member with median seniority is decisive, the marginal income tax rate facing the employed union members should be unambiguously positive and the tax structure unambiguously progressive. If, on the other hand, the union acts according to the utilitarian framework, we can no longer in general rule out regressive tax systems. The third contribution, finally, is by showing that the argument for progressive labor income taxation becomes weaker if the union is able to directly affect the hours of work. The reason is that if 
the union chooses the hours of work for its members, it will recognize that an increase in the hours of work tends to reduce employment.

The outline of the paper is as follows. In section 2, we set up the basic model. Section 3 concerns optimal taxation in case a median voter model for the union determines the wage rate. In section 4 , we analyze the optimal tax structure under the assumption that the union faces a utilitarian objective. Section 5 summarizes the results.

\section{The Model}

Consider an economy where a single good is produced by competitive firms. The firms are identical and their number normalized to unity. Let $N$ be the number of employed persons and $L$ total employment, where the latter is defined as the number of employed persons times the hours of work per employee, $l$. Labor is the only input in the production process, and the production function is given by $F(L)$, where $F_{L}>0$ and $F_{L L}<0$. The objective of the representative firm is to maximize profits, $\pi$, and the objective function is written

$$
\pi=F(L)-w L
$$

where $w$ is the wage rate. The firm chooses labor input according to the first order condition $F_{L}-w=0$, which implicitly defines the labor demand function, $L(w)$, and the profit function, $\pi(w)$. These functions satisfy $L_{w}=1 / F_{L L}<0$ and $\pi_{w}=-L<0$, respectively.

Turning to the consumption side, there are three types of consumers; firm-owners, employed workers and unemployed workers. The consumers have identical preferences defined by the utility function $u(c, z)$, where $c$ is consumption and $z$ leisure. Leisure is, in turn, defined by $z=H-l$ and $H$ is a time endowment. Although the three types of consumers have identical preferences, to be able to distinguish between them we will use $u^{o}(\cdot), u^{e}(\cdot)$ and $u^{u}(\cdot)$ to denote the utility of a firm-owner, an employed worker and an unemployed worker, respectively.

To simplify the analysis, we follow Fuest and Huber (1997) by assuming that all profits accrue to the firm-owners, the number of which is normalized to unity. The firm-owner does not work and profits are untaxed, so his/her utility is given by $u^{o}(\pi, H)$. There are $M$ workers in the labor force, among which $N$ are employed and $M-N$ unemployed. An unemployed 
worker receives a net of tax unemployment benefit, $b$, meaning that his/her utility becomes $u^{u}(b, H)$. An employed worker, on the other hand, faces the budget constraint $c^{e}=I-T(I)$, where $I=w l$ and $T(I)$ is a tax function. The tax function is continuously differentiable, and the marginal and average tax rates are defined as $t^{m}=T_{I}$ and $t^{a}=T / I$, respectively. The representative worker's optimization problem is given by

$$
\begin{aligned}
& \max _{c^{e}, l} u^{e}\left(c^{e}, H-l\right) \\
& \text { s.t. } c^{e}=w l-T(w l)
\end{aligned}
$$

By substituting the budget constraint into the objective function, the first order condition for the hours of work is written

$$
u_{c}^{e}\left(1-t^{m}\right) w-u_{z}^{e}=0
$$

which is standard and needs no further interpretation.

\section{Optimal taxation in the Seniority Union Model}

We assume that all workers are union members. Let us begin by characterizing the wage formation process in terms of the median voter model developed by Oswald (1993), in which the members are ranked according to seniority. The behavior of the union is decided upon by majority voting, meaning that the median union member, who is the person with median seniority, is decisive. The median voter's seniority position will reflect employment levels greater than or equal to $M / 2$. Since employment is assumed to be preferable to unemployment, the aim of the median union member is to achieve the highest possible utility, conditional on being employed.

Suppose that the profits are driven down to some minimum level, $\bar{\pi}$, because of entry or the threat of entry. The optimization problem facing the union can be written as

$$
\max _{w} u^{e}(w l-T(w l), H-l)
$$


s.t. $\pi(w) \geq \bar{\pi}$

$$
N \geq \frac{M}{2}
$$

Note that this formulation implies that either the wage rate or the employment is fixed. Our purpose of using the median voter model is to explore the relationship between work hours and tax progression in case the wage rate is fixed from the point of view of the government. Let us, therefore, follow Oswald by assuming that the first constraint is binding 5 . This means the wage will be fixed at the level implicitly defined by $\pi(w)=\bar{\pi}$. Since the median voter's employment is secured, i.e. $N>M / 2$, the union is locally indifferent to the level of employment. The equilibrium employment is assumed to satisfy $N<M$.

\section{The Optimal Tax Problem}

We assume a utilitarian social welfare function

$$
W=N u^{e}\left(c^{e}, H-l\right)+(M-N) u^{u}(b, H)+u^{o}(\bar{\pi}, H)
$$

The set of policy instruments consists of the unemployment income, $b$, and the parameters of the tax function. Note that, by choosing the parameters of $T(w l)$, the government can induce any desired combination of $c^{e}$ and $l$, meaning that $\left(c^{e}, l\right)$ and the parameters of $T(\cdot)$ constitute two equivalent sets of policy instruments. It is more convenient to use $c^{e}$ and $l$ instead of the parameters of the tax function as decision variables for the government. Given that $c^{e}, l$ and $b$ are chosen in an optimal way from society's point of view, they can be used to construct a tax and expenditure system such that, if implemented in the decentralized economy, the private sector will choose the socially optimal resource allocation.

The government maximizes equation (5) subject to equation (3) as well as subject to two additional constraints. The first is a budget constraint, where the tax revenues are used to finance the unemployment benefit. By using the private budget constraint, $c^{e}=w l-T(w l)$,

\footnotetext{
${ }^{5}$ In this case, it does not matter whether the union treats the hours of work as fixed, or recognizes that the hours of work react to changes in the wage rate. As long as the individuals choose the hours of work conditional on the wage rate, they will obey equation (3), which means that the effects of the wage rate via the hours of work vanish from the first order condition of the union.
} 
and the definition of employment, $N=L(w) / l$, the government's budget constraint can be written as

$$
\left(b+w l-c^{e}\right) \frac{L(w)}{l}-b M=0
$$

The second constraint is a work incentive (WI) constraint, which assures that the state of employment is weakly preferred to the state of unemployment. The WI constraint is given by

$$
u^{e}\left(c^{e}, H-l\right) \geq u^{u}(b, H)
$$

The Lagrangean corresponding to the social optimization problem is written

$$
\begin{aligned}
Z & =\frac{L(w)}{l} u^{e}\left(c^{e}, H-l\right)+\left(M-\frac{L(w)}{l}\right) u^{u}(b, H)+u^{o}(\bar{\pi}, H) \\
& +\mu\left[\left(b+w l-c^{e}\right) \frac{L(w)}{l}-b M\right]+\lambda\left[u^{e}\left(c^{e}, H-l\right)-u^{u}(b, H)\right]
\end{aligned}
$$

The first order conditions become

$$
\begin{aligned}
& \frac{\partial Z}{\partial b}=(M-N-\lambda) u_{c}^{u}-\mu(M-N)=0 \\
& \frac{\partial Z}{\partial c^{e}}=(N+\lambda) u_{c}^{e}-\mu N=0 \\
& \frac{\partial Z}{\partial l}=-\frac{N}{l}\left(u^{e}-u^{u}\right)-(N+\lambda) u_{z}^{e}+\mu w N\left[1-\left(t^{a}+\frac{b}{w l}\right)\right]=0
\end{aligned}
$$

where the subindices denote partial derivatives. Equation (8a) characterizes the socially optimal choice of unemployment income. We can interpret $(M-N) u_{c}^{u}$ to reflect the increase in utility among the unemployed following from a higher benefit, whereas $\mu(M-N)$ captures the welfare cost of raising the necessary tax revenues. Note also that, if the WI 
constraint is binding $(\lambda>0)$, there is an additional welfare cost, $-\lambda u_{c}^{u}$, associated with the unemployment benefit. This is so because an increase in $b$ makes the state of unemployment more attractive relative to the state of employment. Similarly, equation (8b) determines the socially optimal consumption per employee. The first term on the right hand side represents the sum of the direct utility effect per employee of an increase in $c^{e}$ and the effect via the WI constraint, while second term, $\mu N$, means that more private consumption is attained at the expense of reduced tax revenues.

Taken together, equations (8a) and (8b) reflect the socially optimal distribution of consumption between employed and unemployed workers. Using equation (8b) to substitute for $\mu$ in equation (8a), we obtain

$$
u_{c}^{u}=\left(1+\frac{\lambda M}{N(M-N-\lambda)}\right) u_{c}^{e}
$$

The WI constraint influences the possibility of redistribution among employed and unemployed individuals which, it turn, affects the relationship between their marginal utilities of consumption. If the constraint does not bind, then $u_{c}^{u}=u_{c}^{e}$, whereas a binding constraint implies $u_{c}^{u}>u_{c}^{e}$. The intuition is, of course, that the WI constraint works to reduce $b$ relative to $c^{e}$.

Equation (8c) represents the socially optimal choice of hours of work per employee. It can be decomposed into three parts. The first term on the right hand side measures the welfare loss following from a decrease in the number of employed persons. This effect is a consequence of the tradeoff between work hours and employment. The second term is proportional to the negative of the marginal utility of leisure among the employed and represents the direct utility loss from a small increase in the hours of work. The factor of proportionality is given by $N+\lambda$, implying that the influence of the WI constraint is to place a greater weight on this utility loss than otherwise. Finally, the third term measures the welfare effect following the change in tax revenues, if the hours of work increase conditional on the consumption per employee. Such an increase in the hours of work influences the budget constraint facing the government in two distinct ways; (i) it increases the tax revenues per employee, and (ii) it reduces the number of employed workers, which contributes to 
decrease the tax revenues and increase the expenditures on unemployment benefits. It is straightforward to show that

$$
1-t^{a}-b /(w l)=\left(c^{e}-b\right) / w l>0
$$

Let us now continue by analyzing the optimal tax structure implicit in the choices made by the government. By solving equation (8b) for $\mu$, substituting into equation (8c) and then using $u_{c}^{e} w\left(1-t^{m}\right)-u_{z}^{e}=0$ from equation (3), we can derive the following result;

Proposition 1: If the wage rate is decided upon by the union member with median seniority, the optimal tax structure satisfies

$$
t^{m}=t^{a}+\frac{b}{w l}+\frac{N}{(N+\lambda) u_{c}^{e} w l}\left(u^{e}-u^{u}\right)
$$

Following e.g. Musgrave and Musgrave (1984), let us define the degree of tax progression by the ratio $t^{m} / t^{a}$, where $t^{m} / t^{a}>1$ indicates that the tax system is progressive. The following result is an immediate consequence of Proposition 1;

Corollary 1: If the wage rate is decided upon by the union member with median seniority, the marginal tax rate is positive and the tax structure progressive.

The intuition is straightforward. To internalize the external effect from the choice of work hours, the government uses a progressive tax on labor income in order to reduce the hours of work per employee. This effect is captured by the third term on the right hand side. The greater the utility loss of being unemployed, i.e. the greater $u^{e}-u^{u}$, the more progressive the income tax. Note that the unemployment benefit also works to increase the marginal tax rate over the average tax rate. The reason is that the higher the unemployment income, the greater the budgetary cost of unemployment to the government, and the greater the need to increase employment by decreasing the hours of work per employee.

Note also that the WI constraint tends to offset the part of the marginal tax rate that serves to correct for the external effect. If the WI constraint is binding, the final term on the right hand side of equation (9) disappears. This means that the WI constraint tends to reduce the 
marginal tax rate and the degree of tax progression. The intuition is that, if the WI constraint is binding, there is an incentive to make the state of employment more attractive relative to the state of unemployment. The latter is achieved by reducing the marginal tax rate, which increases the utility of the employed.

\section{The Utilitarian Union Model}

An implication of the variant of the seniority model discussed above is that the wage rate is fixed from the point of view of the government. This means that the only possibility for the government to increase the number of employed persons is to decrease the hours of work per employee. In this section, we relax the assumption that the union member with median seniority is decisive and, instead, assume that the union acts in accordance with a utilitarian objective function. As is standard, we will not impose any minimum restriction on profits in what follows, meaning that neither the wage rate nor the employment will be fixed. The objective function facing the union is given by

$$
U=N u^{e}(w l-T(w l), H-l)+(M-N) u^{u}(b, H)
$$

The union chooses the wage rate conditional on $l$ and $b$ to maximize equation (10) subject to $N=L(w) / l$. By assuming an interior solution for employment, $N<M$, the first order condition can be written as ${ }^{6}$

$$
U_{w}=\frac{L_{w}}{l}\left(u^{e}-u^{u}\right)+\left(1-t^{m}\right) u_{c}^{e} L=0
$$

\footnotetext{
${ }^{6}$ The monopoly union model used here is a special case of the more general right-to-manage model, where the union and the firm bargain over the wage rate, and the firm then chooses employment conditional on the wage rate. As long as the wage rate exceeds the market clearing wage rate, the qualitative results to be derived below are not particularly sensitive to whether the wage rate is chosen by a monopoly union or the outcome of a more general bargaining model. In fact, if a right-to-manage framework replaces the monopoly union assumption, the wage rate will be a function of the policy instruments in a way similar to equation (12) below. This made us choose the monopoly union model over the more computationally burdensome right-to-manage model. See Oswald (1985) for a review of models commonly used to describe unionized labor markets. Another possible extension of the model set out above is to assume that the union behaves as a Stackelberg leader in the sense of recognizing that its choice of wage rate will influence the hours of work. We will not consider this possibility here. Instead, to analyze the consequences of assuming that the union is able to influence the choice of work hours, in the final part of this section we consider the situation where the union both chooses the wage rate and the hours of work per employee.
} 
We assume that the second order condition, $U_{w w}<0$, is satisfied. It is straightforward to show that the wage rate chosen by the union increases with $b$ and $t^{a}$, and decreases with $t^{m}$.

\section{The optimal Tax Problem}

To begin with, let us assume that those who become employed can freely choose their hours of work conditional on the wage rate. In this case, equations (3) and (11) constitute the necessary conditions of the private sector by determining the hours of work per employee and the wage rate, respectively. It will be convenient to rewrite equation (11) by eliminating the term $\left(1-t^{m}\right)$. By using equation (3), we can rewrite equation (11) as

$$
L_{w}(w)\left[u^{e}\left(c^{e}, H-l\right)-u^{u}(b, H)\right]+\frac{l L(w) u_{z}^{e}\left(c^{e}, H-l\right)}{w}=0
$$

Equation (12) implicitly defines a reduced form wage equation, $w\left(b, c^{e}, l\right)$, in terms of the decision variables of the government. The comparative static properties of this function are given in the Appendix.

The Lagrangean of the optimal tax problem is written

$$
\begin{aligned}
Z & =N u^{e}\left(c^{e}, H-l\right)+(M-N) u^{u}(b, H)+u^{o}\left(\pi\left(w\left(b, c^{e}, l\right)\right), H\right) \\
& +\mu\left[\left(b+w\left(b, c^{e}, l\right) l-c^{e}\right) N-b M\right] \\
& +\lambda\left[u^{e}\left(c^{e}, H-l\right)-u^{u}(b, H)\right]
\end{aligned}
$$

By using $N=L\left(w\left(b, c^{e}, l\right)\right) / l$, the first order conditions become

$$
\begin{aligned}
& \frac{\partial Z}{\partial b}=(M-N-\lambda) u_{c}^{u}-\mu(M-N)+\frac{\partial W}{\partial w} \frac{\partial w}{\partial b}=0 \\
& \frac{\partial Z}{\partial c^{e}}=(N+\lambda) u_{c}^{e}-\mu N+\frac{\partial W}{\partial w} \frac{\partial w}{\partial c^{e}}=0 \\
& \frac{\partial Z}{\partial l}=-\frac{L}{l^{2}}\left(u^{e}-u^{u}\right)-(N+\lambda) u_{z}^{e}+\mu w N\left[1-\left(t^{a}+\frac{b}{w l}\right)\right]+\frac{\partial W}{\partial w} \frac{\partial w}{\partial l}=0
\end{aligned}
$$


Note that, since the social welfare function equals the Lagrangean at the optimum, and by defining $\varepsilon=L_{w} w / L$ to be the wage elasticity of the labor demand, we have

$$
\frac{\partial W}{\partial w}=\frac{L_{w}}{l}\left(u^{e}-u^{u}\right)-L u_{c}^{o}+\mu L\left[1+\varepsilon\left(t^{a}+\frac{b}{w l}\right)\right]
$$

Equations (13a), (13b) and (13c) differ from their counterparts in section 3, because the wage rate here depends on the decision variables of the government. The final term on the right hand side of each necessary condition reflects the influence of that policy instrument on the wage rate times the welfare effect of an increase in the wage rate. Note from equation (13d) that the latter is ambiguous; the first two terms on the right hand side are negative, whereas the third term can be either positive or negative depending on how the tax revenues and expenditures respond to an increase in the wage rate.

By analogy to the analysis carried out in the previous section, we can derive the following result;

Proposition 2: If the union acts in accordance with a utilitarian objective, and the individual workers choose the hours of work, the optimal tax structure satisfies

$$
t^{m}=t^{a}+\frac{b}{w l}+\frac{N}{(N+\lambda) u_{c}^{e} w l}\left(u^{e}-u^{u}\right)+\beta \frac{\partial W}{\partial w}
$$

where

$$
\beta=-\frac{1}{(N+\lambda) u_{c}^{e} w l}\left[\frac{\partial w}{\partial c^{e}} c^{e}-\frac{\partial w}{\partial c^{e}} b+\frac{\partial w}{\partial l} l\right]
$$

The first three terms on the right hand side of equation (14) are equivalent to their counterparts in equation (9). Therefore, the second and third terms on the right hand side contribute to increase the marginal tax rate over the average tax rate. The fourth term, on the other hand, can be either positive or negative. This additional part of the implicit expression for the marginal tax rate is explained by the fact that the government is now able to affect 
employment both via the hours of work per employee (as before) and via the influence of each policy instrument on the wage rate. The interpretation is that, in comparison with the situation where the policy instruments have no influence on the wage rate, the government now has a more comprehensive set of mechanisms to use in order to affect the employment. The government is, therefore, no longer necessarily restricted to use a progressive tax.

By analogy to equation (9), the purpose of the third term on the right hand side of equation (14) is to internalize the external effect associated with the hours of work. However, although there is an external effect, due to the tradeoff between the number of employed persons and the hours of work per employee, a small decrease in the hours of work per employee does not necessarily contribute to increase employment, if the union behaves according to the utilitarian framework. This is so because $\partial w / \partial l$ can in general be either positive or negative. If the union responds to an increase in the hours of work per employee by lowering the wage rate, there is a tendency for employment to increase which may, in turn, offset the direct negative effect on employment following from an increase in the hours of work per employee. Note also that a negative relationship between the wage rate and the hours of work per employee is not a necessary condition for the tax structure to be regressive. The reason is that $\partial W / \partial w$ and $\partial w / \partial c^{e}$ can be either positive or negative. In other words, even if we were to assume that a decrease in the hours of work increases employment, which provides an argument for progressive taxation, the other policy instruments may, nevertheless, work the other way around.

\section{The Optimal Tax Structure when the Hours of Work are chosen by the Union}

The results derived above are based on the assumption that those who become employed are able to freely choose their hours of work. This means that the preferences and constraints of the employed determine the hours of work. If, on the other hand, the utilitarian union chooses the hours of work, it will recognize the relationship between work hours and the number of employed persons, meaning that the external effect might become internalized. This would weaken the argument for progressive taxation. In the context of the literature on union wage setting, there seems to be no standard approach about how the hours of work per employee are determined. It is, therefore, interesting to consider the situation where the hours of work are 
chosen by the union ${ }^{7}$. If the union chooses the hours of work per employee, equation (3) is replaced by

$$
\frac{\partial U}{\partial l}=-\frac{L}{l^{2}}\left(u^{e}-u^{u}\right)+N\left[\left(1-t^{m}\right) w u_{c}^{e}-u_{z}^{e}\right]=0
$$

Taken together, equations (15) and (11) now determine the hours of work and the wage rate, respectively, conditional on the policy variables. Note that, for a given wage rate, equation (15) implies that the union chooses fewer hours of work than would be chosen by the individual himself/herself, since the union recognizes that an increase in the hours of work reduces the number of employed persons.

Consider Proposition 3;

Proposition 3: If both the hours of work per employee and the wage rate are chosen by a union with a utilitarian objective, the optimal tax structure satisfies

$$
t^{m}=t^{a}+\frac{b}{w l}+\beta \frac{\partial W}{\partial w}
$$

The difference between equations (14) and (16) is that the third term on the right hand side of equation (14) is not part of equation (16). This is so because, if the union chooses the hours of work per employee, the external effect associated with the choice of work hours will be internalized. The following result is an immediate consequence of Propositions 2 and 3;

Corollary 2: If the WI constraint does not bind, and the union chooses the hours of work per employee, the marginal tax rate is likely to be lower and the tax structure less progressive than when the employed individuals choose the hours of work themselves. With a binding WI constraint, the two tax formulas become identical, and it is no longer possible to distinguish the incentives underlying taxation across regimes.

\footnotetext{
${ }^{7}$ Similar ideas have been put forward in other studies. See e.g. Fuest and Huber (2000), who analyze whether tax progression increases or decreases employment. They carry out their analysis both in the situation where the employed union members freely choose their hours of work conditional on the wage rate, and the situation where the hours of work per employee are determined by bargaining between the union and the firm.
} 


\section{Summary and Discussion}

The purpose of this paper is to study the optimal degree of tax progression in a unionized economy. The analysis is based on a general equilibrium model, where the hours of work are endogenous, and that the government faces a utilitarian objective. Two versions of the labor market part of the model are being discussed; one in which the union member with median seniority is decisive, and the other where the union acts in accordance with a utilitarian objective function. This comparison is interesting, since a variant of the former model means that the wage rate is fixed from the point of view of the government. We also distinguish between the situation where the employed individuals choose the hours of work conditional on the wage rate, and the situation where the union chooses the hours of work. The latter distinction is relevant for optimal taxation. If the employed were able to choose the hours of work themselves, then individual preferences determine the hours of work, whereas a union with preferences for employment also recognizes a tradeoff between the number of employed persons and hours of work per employee. As such, the assumptions underlying how the hours of work are chosen will be important for the tax structure.

Since employed individuals do not consider the tradeoff between the number of employed persons and the hours of work per employee, there will be an incentive to use a progressive tax system for the purpose of reducing the hours of work. We show that if the union member with median seniority is decisive, in which case the wage rate is fixed from the point of view of the government, the marginal income tax rate facing the employed union members should be unambiguously positive and the tax structure unambiguously progressive. If, on the other hand, the union acts according to the utilitarian framework, we can no longer in general rule out regressive tax systems. In this case, the wage rate will be a function of the policy instruments, meaning that the government has a broader set of mechanisms via which to influence the resource allocation. Therefore, if the wage rate depends on the tax system, it may no longer be necessary to use a progressive income tax in order to influence employment in the way the government desires. We also show that the argument for progressive labor income taxation becomes weaker, if the union is able to directly affect the hours of work.

\section{Appendix}

The comparative static properties of the function $w\left(b, c^{e}, l\right)$ are 


$$
\begin{aligned}
& \frac{\partial w}{\partial b}=\frac{L_{w} u_{c}^{u}}{\alpha} \\
& \frac{\partial w}{\partial c^{e}}=-\frac{L\left(\varepsilon u_{c}^{e}+l u_{c z}^{e}\right) / w}{\alpha} \\
& \frac{\partial w}{\partial l}=-\frac{L\left((1-\varepsilon) u_{z}^{e}-l u_{z z}^{e}\right) / w}{\alpha}
\end{aligned}
$$

where

$$
\alpha=L_{w w}\left(u^{e}-u^{u}\right)-l L u_{z}^{e}(1-\varepsilon) / w^{2}
$$

\section{References}

Aronsson, T., Wikström, M. and Brännlund, R. (1997) "Wage determination under non-linear taxes: Estimation and an application to panel data". Oxford Economic Papers 49, 404-418.

Aronsson, T. and Sjögren, T. (2001) "Income taxation, commodity taxation and provision of public goods under labor market imperfections”. Department of Economics, Umeå University.

Boeters, S. and Schneider, K. (1999), “Government versus union: The structure of optimal taxation in a unionized labor market”, Finanzarchiv 56, 174-187.

Fuest, C. and Huber, B. (1997), "Wage bargaining, labor-tax progression, and welfare", Journal of Economics 66, 127-150.

Fuest, C. and Huber, B. (2000) "Is Tax Progression Really Good for Employment? A Model with Endogenous Hours of Work". Labour Economics 7, 79-93. 
Hersoug, T. (1984), “Union wage responses to tax changes”, Oxford Economic Papers 36, 3751.

Hoel, M. (1989), “Income taxes and non-market clearing wages”, University of Oslo, mimeo.

Holmlund, B. And Kolm, A-S. (1995) "Progressive Taxation, Wage Setting and Unemployment - Theory and Swedish Evidence". Swedish Economic Policy Review 2, 423460.

Koskela, E. and Schöb, R. (2000), "Optimal factor income taxation in the presence of unemployment", Center for Economic Studies, Working paper No 279.

Layard, R. (1982), “Is incomes policy the answer to unemployment?”, Economica 49, 219239.

Lockwood, B. and Manning, A. (1993), "Wage setting and the tax system”, Journal of Public Economics 53, 1-29.

Malcolmson, J. M. and Sartor, N. (1987), “Tax push inflation in a unionized labour market”, European Economic Review 31, 1581-1596.

Oswald, A.J. (1985) "The Economic Theory of Trade Unions: An Introductory Survey". The Scandinavian Journal of Economics 87, 160-193.

Oswald, A., J. (1993), "Efficient contracts are on the labour demand curve: Theory and facts", Labour Economics 1, 85-114.

Palokangas, T. (1987), "Optimal taxation and employment policy with a centralized wage Setting", Oxford Economic Papers 39, 799-812.

Sandmo, A. (1983), "Progressive taxation, redistribution and labour supply", Scandinavian Journal of Economics 85, 311-323. 
Musgrave, R, and Musgrave, P. B. (1984), Public finance in theory and practice, New York: McGraw-Hill. 